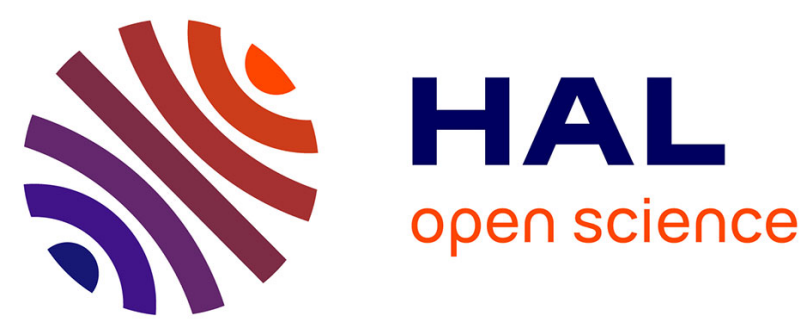

\title{
HIGH RESOLUTION NMR STUDIES OF HISTONES AND THEIR INTERACTIONS WITH DNA
}

\author{
E. Bradbury, P. Cary, C. Crane-Robinson, H. Rattle
}

\section{To cite this version:}

E. Bradbury, P. Cary, C. Crane-Robinson, H. Rattle. HIGH RESOLUTION NMR STUDIES OF HISTONES AND THEIR INTERACTIONS WITH DNA. Journal de Physique Colloques, 1973, 34 (C8), pp.C8-25-C8-37. 10.1051/jphyscol:1973813 . jpa-00215366

\section{HAL Id: jpa-00215366 https://hal.science/jpa-00215366}

Submitted on 1 Jan 1973

HAL is a multi-disciplinary open access archive for the deposit and dissemination of scientific research documents, whether they are published or not. The documents may come from teaching and research institutions in France or abroad, or from public or private research centers.
L'archive ouverte pluridisciplinaire HAL, est destinée au dépôt et à la diffusion de documents scientifiques de niveau recherche, publiés ou non, émanant des établissements d'enseignement et de recherche français ou étrangers, des laboratoires publics ou privés. 


\title{
HIGH RESOLUTION NMR STUDIES OF HISTONES AND THEIR INTERACTIONS WITH DNA
}

\author{
E. M. BRADBURY, P. D. CARY, C. CRANE-ROBINSON and H. W. E. RATTLE \\ Biophysics Laboratories, Physics Department, Portsmouth Polytechnic, Portsmouth, \\ Hants, England
}

\begin{abstract}
Résumé. - Le complexe chromosomique comprend des poids à peu près égaux d'ADN et de protéines (histones), ainsi qu'une quantité variable de protéines non histones. La distribution très irrégulière des acides aminés dans les cinq fractions d'histones principales F1, F2B, F2A1, F2A2, F3 permet de déterminer les réactions des molécules qui interviennent dans les interactions histonehistone. Une addition de sel aux solutions d'histones provoque la formation de structures secondaires vues par un élargissement des résonances des parties les moins basiques de la chaîne polypeptidique. On en déduit que celles-ci sont mises en jeu dans les structures intra et intermoléculaires. Une technique de simulation est utilisée dans l'analyse des spectres. En présence d'ADN, l'élargissement des pics concerne les régions les plus basiques des histones, qui sont donc mises en jeu lors des interactions avec l'ADN. Les histones sont ainsi considérées comme créant des changements conformationnels dans la chromatine du fait que seules certaines régions de la chaîne polypeptidique se lient à l'ADN alors que les autres interviennent dans les interactions histone-histone. Un modèle d'action de la fraction Fl est proposé.
\end{abstract}

\begin{abstract}
The chromosomal complex consists of an approximately equal weight of DNA and basic protein (histones) together with a variable amount of non-histone (acidic) protein. Lack of tissue or even organism specificity and extreme immutability suggests a broad structural role for histones in processes of gene control and chromosomal condensation rather than a role of high specificity in recognition of DNA base sequence or as a target for repressor/derepressor molecules. The highly irregular distribution of amino acids in the 5 main histone fractions F1, F2B, F2A1, F2A2, F3 has permitted a determination of which sections of the molecules can participate in histone-histone interactions. Addition of salts to histone solutions results (for all except F1) in the formation of secondary structures resulting in specific broadening of resonances from the less basic portions of the polypeptide chain. It is concluded that these are involved in intra and intermolecular structures. An empirically based spectrum simulation technique is used to aid the analysis. In the presence of DNA broadening is observed of resonances from the more basic regions of the histones and it is concluded that these are the sites of interaction with DNA. Histones are therefore envisaged as bringing about structural changes in chromatin by virtue of the fact that only certain parts of the polypeptide chain - (in most cases the $\mathrm{N}$ and $\mathrm{C}$ terminal regions) bind to DNA whilst the remainder takes part in histone/histone interactions that are susceptible to external influences. Interactions of the very lysine rich histone $F 1$ have been studied in chromatin gel itself by following the changes in the NMR spectrum accompanying the salt-induced release of this protein. Correlation of the spectral changes and other data with the state of the gel has resulted in a model for the mode of action of $F 1$.
\end{abstract}

1. Introduction. - - In all tissues of higher organisms histones comprise the largest protein component of the cell nucleus. Their high basic charge and close association with DNA has led to two suggestions concerning their function. The first of these is the original hypothesis of Stedman and Stedman [1] that histones are involved in control mechanisms of genetic regulation. At the time of this proposal it was thought that there were many hundre's of different histones. However, it is now known that such high numbers resulted from artifacts of preparation and that there is only a relatively small number of these proteins, probably less than 12. Further in spite of many experiments there have been no clear cut results implicating histones in precise control mechanisms. Distinction should, however. be made between the precise control of active genes in differentiated tissues and the gross inactivation of the 
very large number of non-functioning genes. Histones are probably involved in the latter process either simply through covering the inactive parts of the genome or through controlling the conformation of the DNA in these regions. The similarity of the histones from different tissues and organisms also argues against the involvements of histones in precise control mechanisms. This similarity has been shown by the identical sequences of porcine [2] and bovine [3] F2A1 histone and more dramatically by the sequence of the same histone from pea seedling [4] in which only 2 conservative replacements were found. In view of the number of intermediate and highly mutable sites found in the sequences of enzymes such a rigid conservation of sequence of histone F2A1 and the similarity of other histones implies a highly specific function involving exact conformations and probably precisely controlled conformational changes of the whole polypeptide chain.

The second of the proposed roles is that histones are largely structural proteins and are involved in controlling the conformational changes which DNA molecules undergo during mitosis. The stringent requirements of this role are illustrated by the degree of condensation or coiling of DNA required during this process in which DNA molecules of the order of centimetres to metres long are packed into a compact chromosome of the order of microns. The process is reversible and must demand considerable precision in the histone conformations, changes in conformation, histone - DNA interactions and histone - histone interactions. Unfortunately, detailed conformations of histones have not been obtained from the usual structural technique of X-ray diffraction due to the very diffuse nature of their diffraction patterns [5]. It is probable from the above discussion that this is a consequence of their function since histones do not have the rigid structures of enzymes and are unlikely to form single crystals. It has been necessary, therefore, in studying the conformational behaviour of histones and their interactions with DNA to use other techniques and high resolution NMR spectroscopy has so far proved to be the most powerful of the available techniques.

A reason for the success of the application of NMR to these problems is to be found in the unique nature of the histone sequences so far determined. The sequences of the histones F2A1, F2B [6], F2A2 [7], [8] and $F 3$ [9] and the partial sequence and analyses of peptides from $\mathrm{F} 1$ [10] show considerable nonuniformity in the distribution of residues along the polypeptide chains. All histone sequences contain regions which are very rich in basic and helix destabilising residues and other regions which have low basicity and contain a high proportion of helix forming residues (see ref. [11] for description of properties of different residues), aromatic and other active residues such as serine, threonine and acidics. These features have led to the suggestion that the very basic regions are the primary sites for interaction with DNA - while the other regions are the most likely to contain any secondary conformation such as the $\alpha$-helix and be involved in protein-protein interactions. Because of this highly non-uniform distribution of residues in these proteins it has proved possible to use high resolution NMR spectroscopy to locate those regions of the polypeptide chains in which the mobilities of residues have been restricted by inclusion in helical segments and in interactions with other histone molecules or with DNA. Residues which are located specifically in different regions of the polypeptide chain are used to report on the mobilities of that part of the chain.

There are two basic assumptions involved in these studies; the first is that increasing the ionic strength of aqueous solutions induces conformational changes and interhistone interactions similar to those found in the ionic environment of DNA. The second assumption is that marked apparent loss in area of only certain resonance peaks (when compared to other peaks in the same NMR spectrum) is a result of dipolar broadening due to restricted motion of specific regions of the polypeptide chain for one or other of the reasons given above. Since histone molecules consist of single polypeptide chains and paramagnetic ions are excluded from the system the latter assumption is most probably valid. The former assumption can be verified when the interaction of histones in chromatin can be studied. Recently it has been found that the interactions of the very lysine rich histone can be followed in chromatin on varying the ionic strength. As will be shown later the segment of the $\mathrm{F} 1$ molecules involved in interchain interaction in the chromatin gel is the same as found for the isolated $\mathrm{Fl}$ molecules in aqueous salt solutions.

2. NMR studies of histone fractions. - Early high resolution NMR studies were carried out largely at $100 \mathrm{MHz}$ with some additional studies at $220 \mathrm{MHz}$. These showed for F1 and F2A1 [12] and F2B [13] that in aqueous solutions the proteins are largely in the random coil form giving well defined high resolution NMR spectra which agree fully with the spectrat expected from the amino acid compositions. With increase of ionic strength only certain of the resonance peaks show a marked diminution in apparent peak area. The spectral changes correspond to a loss of mobility of residues in specific regions of the polypeptide chain; the regions involved are those with a low content of basic residues and a high content of residues with a high potential for helix formation. Optical spectroscopic studies [14] show also that the histones are largely in the random coil conformation in water and increase of ionic strength results in an increase in helix content to $25-30 \%$ for all the fractions except for FI, for which appreciably smaller effects are observed. These changes together with the NMR spectral changes suggest that the salt- 
induced helical segments were located in the specific regions of the histone polypeptide chains which have restricted mobilities. Preliminary studies of the interactions of histones $\mathrm{F} 2 \mathrm{~B}$ and $\mathrm{F} 1$ with DNA have been reported [15]. For F2B it was found that resonances from residues in the basic regions of the molecule were specifically broadened in the interaction with DNA while the non-basic segments previously shown to be involved in salt-induced interhistone interaction became more mobile.

These interaction studies have now been considerably extended along the following lines:

2.1 Computer simulations of spectra. - These allow a more objective analysis of the histone spectra and spectral changes.

2.2 THE SELF-INTERACTIONS OF HISTONES INDUCED BY SALT AND PH CHANGES. - It has been shown by the applications of computer simulation of spectra that it is possible to delineate specific segments of the histone molecule involved in interchain interactions. These are the non-basic regions and models for some of the interactions have been proposed.

2.3 Histone fragments. - In collaboration with E. W. Johns of the Chester Beatty Research Institute histone F2B has been cleaved at methionine 59 and 62 to give large quantitities of the separated halves. Similarly with J. Palau (Barcelona) F1 has been cleaved at tyrosine 72 to give the fragments 1 to 71 and 73 to 216 . The conformations and interactions of these fragments have been studied and the results compared with those obtained from the whole molecules.

2.4 INTERACTIONS OF HISTONES WITH DNA. Preliminary studies have been made of the interactions of histones F2B, F2A2, F2A1 and F3 with DNA which show that specific segments of these molecules are the primary sites of interaction with DNA.

2.5 InTERACTION OF histones IN CHROMATIN. It has been found that NMR signals can be observed in chromatin gel. These are from the lysine rich histones $\mathrm{Fl}$ and interactions of the Fl molecules in the gel have been followed on changing the salt molarity. A model for the role of $\mathrm{Fl}$ histone in chromatin has been proposed.

2.1 to 2.5 above can now be discussed in more detail.

2.1 COMPUTER SIMULATION OF HISTONE SPECTRA [16]. - The conclusions drawn in earlier publications [17], [13] were obtained from a visual inspection of the spectral changes induced in the histones either by salt or by their interactions with DNA [15]. Much of the information contained in these results was not fully utilised, i. e. only prominent spectral changes have been analysed whereas there are interesting changes in the shapes of the envelopes of overlapping resonance peaks. To make fuller use of the results obtained programmes have been written for the computer simulation of histone spectra and of the induced spectral changes [16]. A standard peak shape is used having been modified from an original Gaussian shape by trial fittings to observed NMR line shapes. A Gaussian shape was chosen go start since nearly all the peaks under consideration are multiplets whose intensities are distributed binomially. One " resonance peak " was generated for each chemical group of the protein and specified on a punched card by its position on a frequency scale, area in arbitrary units representing the number of protons contributing to the peak and the width in $\mathrm{Hz}$. Peaks representing all groups of protons in the protein were fed into the computer and the whole plotted as a simulated spectrum. For the random coil conformation of all the histone fractions a very close fit was obtained between observed and simulated spectra. The simulated spectra could then be modified by e. g. broadening out the peaks corresponding to a given section of the protein and comparing in detail the resultant changes in the envelope of the spectrum with those observed in the real spectra of histones when the solution conditions were changed or the histones were allowed to interact with DNA. It was found that the modified simulated spectra approached the real spectra in $\mathrm{NaCl} / \mathrm{D}_{2} \mathrm{O}$ solutions only when peaks corresponding to closely defined sections of the molecule were broadened. For example the segments of histone F2B defined in this way were similar, but not identical, to those proposed by visual comparison of the spectral changes. Thus whereas the visual comparison of spectral changes led to the suggestion that the segment of $\mathrm{F} 2 \mathrm{~B}$ from 60 to 102 is involved in the conformational changes and histone interactions [13], the computer comparison of spectral changes gave the closest fit when peaks from residues 31 to 102 were broadened. The computer simulation allows a more detailed comparison of the spectral changes than is possible with visual inspection and therefore allows more detailed conclusions to be made.

2.2 and 2.3. - The self-interaction of histones and histone fragments induced by salt and $\mathrm{pH}$ changes.

As an example of the approach the study of histone F2B will be discussed in some detail.

a) F2B. - The effect of increase in salt molarity and change of $\mathrm{pH}$ on the conformations and interactions of histone $\mathrm{F} 2 \mathrm{~B}$ have been studied by optical and high resolution NMR spectroscopy. Optical rotatory dispersion studies [14], [17], [18] show that F2B in water is in the random coil conformation. Increase in salt molarity or $\mathrm{pH}$ causes an increase in the ORD parameters characteristic of a helical conformation to give about $30 \%$ helix at $1.0 \mathrm{M} \mathrm{NaCl}$. The absence of the extended $\beta$-conformation can be demonstrated by infrared spectroscopy. NMR studies 
of F2B [13] shows that only specific resonance peaks are broadened by the salt- and $\mathrm{pH}$-induced conformational changes and interactions. These are the apolar residues, valine, leucine and isoleucine, the arginine residues, acidic and aromatic residues. A visual analysis of the spectral changes suggested that segment 60 to 102 was involved in the induced conformational changes and interactions. More recently, a computer simulation [16] of the random coil F2B NMR spectrum and the salt modified spectra show that the best fit between observed and calculated spectra is obtained when the resonances from residues in the segment 31 to 102 are broadened. It is suggested therefore that this segment is involved in salt and $\mathrm{pH}$ induced conformational changes and interactions in histone F2B.

The above conclusions were largely confirmed by cleaving F2B at methionines 59 and 62 with cyanogen bromide and studying the salt-dependent conformational behaviour and interactions of each half of the molecule [18]. Striking differences in behaviour were observed. ORD results showed that the amino half of F2B 1 to 58 remained fully in the random coil form, from 0 to $2.5 \mathrm{M} \mathrm{NaCl}$. The NMR changes showed, however, that interchain interactions could be induced at very high salt between the half molecules at segment 31 to 50 . In contrast to the behaviour of the amino half of the molecule the carboxyl half of F2B was found to show considerable changes both in the ORD parameters and in the NMR spectra at much lower salt molarities. The ORD results showed that the carboxyl half of F2B was in the random coil form in water but increase of salt molarity caused a rapid conformational change to about $60 \%$ helix content at $0.7 \mathrm{M} \mathrm{NaCl}$. The total helix content of the whole of F2B is thus contained in the carboxyl half of the molecule. Marked changes in the NMR spectra were observed on going from water to $0.7 \mathrm{M}$ $\mathrm{NaCl}$. At the higher salt molarity the segment of the carboxyl half of F2B which has its mobility restricted by the conformational changes and interchain interactions was found to be 66 to 102. These results showed therefore that the same regions of the half molecules were involved in conformational changes and interactions as found for the whole molecule. For the whole molecule the segment was found to be 31 to 102, while for the half molecules it was 31 to 50 and 66 to 102. Not unexpectedly some of the residues adjacent to the cleavage sites are mobile in the half molecules at high salt. In general, however, the averages of the ORD parameters and of the NMR spectra of the half molecules are the same as observed for the whole molecule. It follows that as regards salt-induced conformational changes and interactions the behaviour of each half of the molecule is largely independent of the other half which supports one general proposal that regions of histones with different character, as regards their amino acid composition, have distinct functions. As will be shown later the segments of the F2B molecule not involved in the salt induced conformational changes and interactions i. e. 1 to 30 and 102 to 125 are precisely the segments which interact with DNA.

Similar studies are being performed with histones F2A1, F2A2 and F3; the work so far has been concerned with the whole molecules.

b) F2A1. - Early studies suggested that the segment of F2A1 involved in salt-induced conformational changes and interactions was the carboxyl half of the molecule [12]. Computer simulation of spectra [16] give the best fit between observed and calculated spectra for the segment 31 to 102. This is identical in length and position to the segment found for histone $F 2 B$ and the overall compositions of this segment for both molecules is very similar.

c) F2A2. - The recent sequence determination [7], [8] of this protein has allowed analysis of the NMR spectral changes on increase in ionic strength. Similar to G2B ORD studies [19] showed that F2A2 was largely in the random coil in water and increase of the salt molarity to $1 \mathrm{M} \mathrm{NaCl}$ resulted in an increase in helicity to $30 \%$. The NMR spectra over the same range of salt molarities show broadening and loss in apparent area of specific peaks only. As can be seen in figure 1 the peaks markedly affected are the

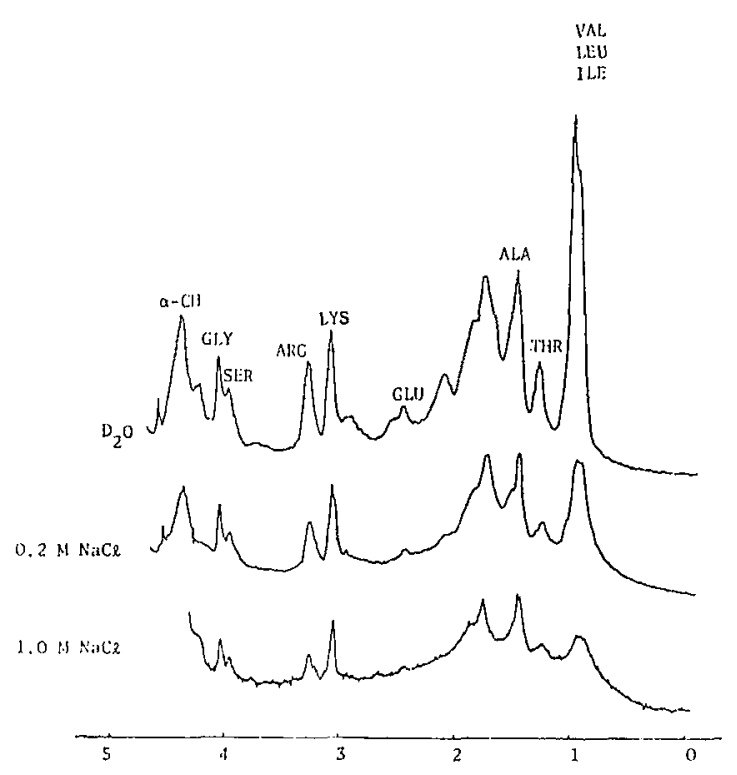

FIG. 1.

$0.93 \mathrm{ppm}$ from the methyl groups of valines, leucines and isoleucines and the $\mathrm{CH}_{2}$ resonances of glutamic acid residues. More dramatic effects are seen for the resonances from aromatic residues shown in the spectra in figure 2. In water solution the resonances of the 4 histidines at positions $31,82,123$ and 124 1 phenyl alanine at 25 and 3 tyrosines at 39,50 and 57 are well developed. Increasing the salt molarity to $0.2 \mathrm{M} \mathrm{NaCl}$ results in the broadening and apparent loss in area of the tyrosines. Clearly the segment 


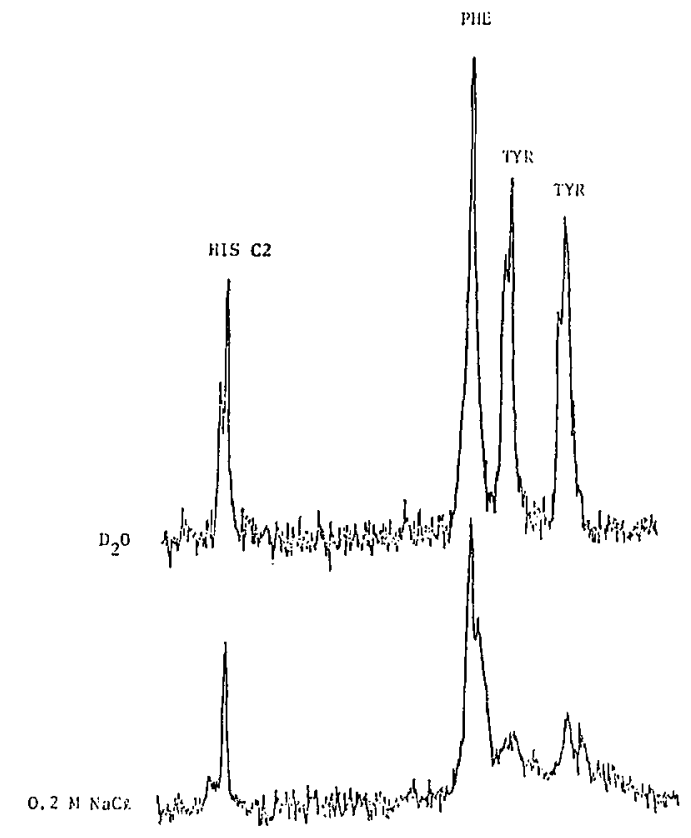

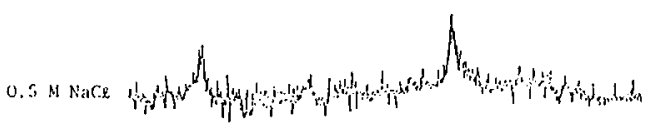

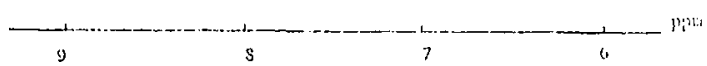

FIG. 2.

involved in the initial conformation and interchain interactions is that which includes the tyrosine at 39,50 and 57 . By $0.5 \mathrm{M} \mathrm{NaCl}$ the resonance from phenylalanine 25 is broadened and resonances from some of the histidines are also affected. The segment involved in the conformational changes and interactions must therefore be extended to include histidine 31 and phenylalanine 25. Although not complete, computer simulations suggest that the segment from 25 to at least residue 92 is involved in the conformational changes and interactions. As can be seen from figure 3 this segment is rich in apolar, aromatic and acidic residues

d) F3. - The recent sequence of F3 [9] has allowed the NMR studies to proceed. The upfield spectra showing the effects of increasing salt molarity are shown in figure 4 while the spectra of the aromatic resonances are given in figure 5. Again differential broadening effects are observed. An analysis similar to that for $\mathrm{F} 2 \mathrm{~A} 2$ above leads to the tentative suggestion that the segment involved in the conformational transition and interchain interactions is from 40 to close to the end of the molecule.

3. Lysine rich histones. - There are many features which distinguish the lysine rich histones from the other histones. They are the most basic of the histones and are approximately twice as big, having a molecular weight of 21,000 compared to a range of 11.000

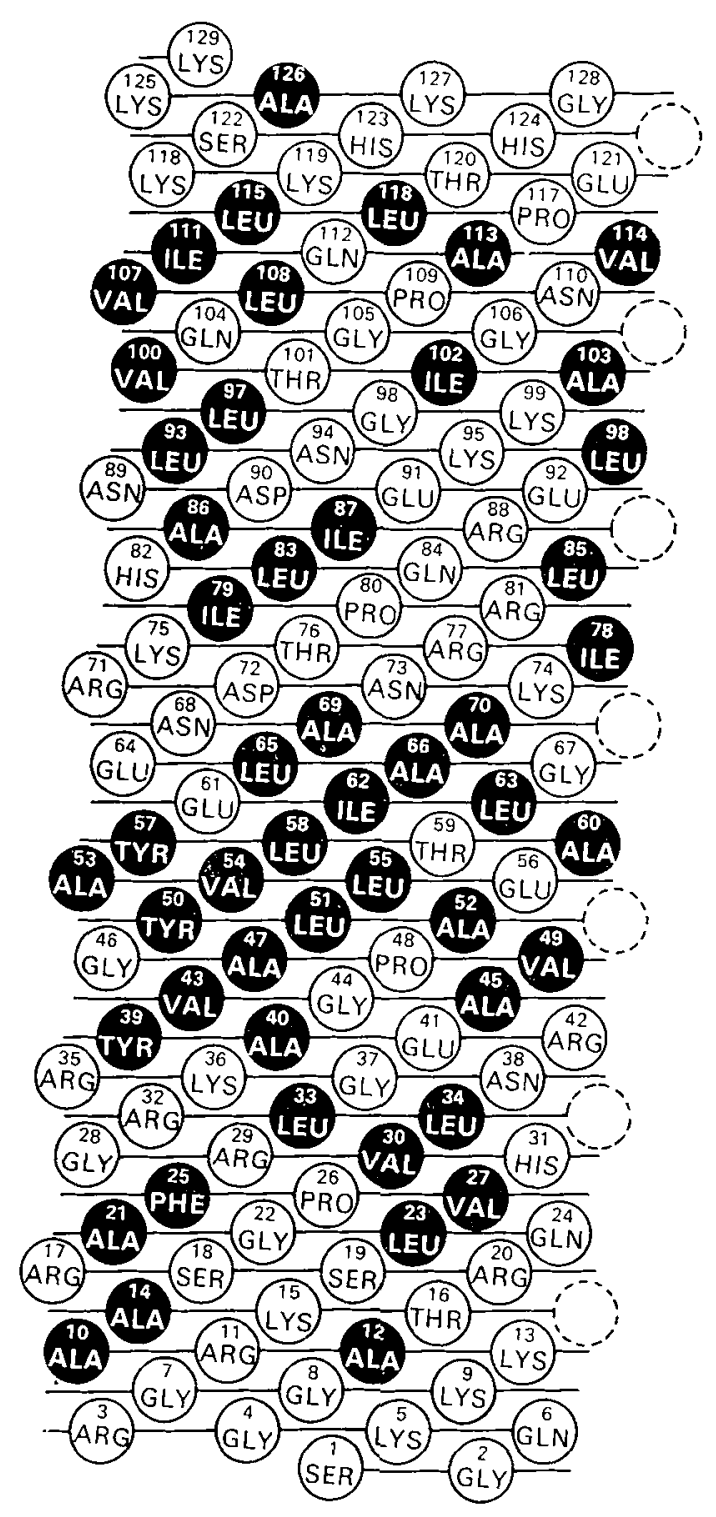

FIG. 3.

to 15,000 found for the others. In spite of the high basic charge they are the first histones to be dissociated from the chromatin complex on increase of ionic strength with simplesalts. Of all the histones the lysine rich histones show the most variability. Thus Cole and his coworkers [20] have shown the presence of microheterogeneity in rabbit thymus $\mathrm{Fl}$ histones and have suggested that differences in patterns of microheterogeneity are related to tissue specificity. The most striking example of tissue specificity, however, is to be found for the chicken erythrocyte lysine rich histone F2C which largely, though not completely replaces the $\mathrm{Fl}$ histones found in other tissues. $\mathrm{F} 2 \mathrm{C}$ is more basic than $\mathrm{Fl}$ and contains an appreciably higher proportion of arginine. Palau et al. [21] has found that the lysine rich histone from sea urchin sperm $\varphi 1$ also contains a higher proportion of arginine and suggests that the more meta- 


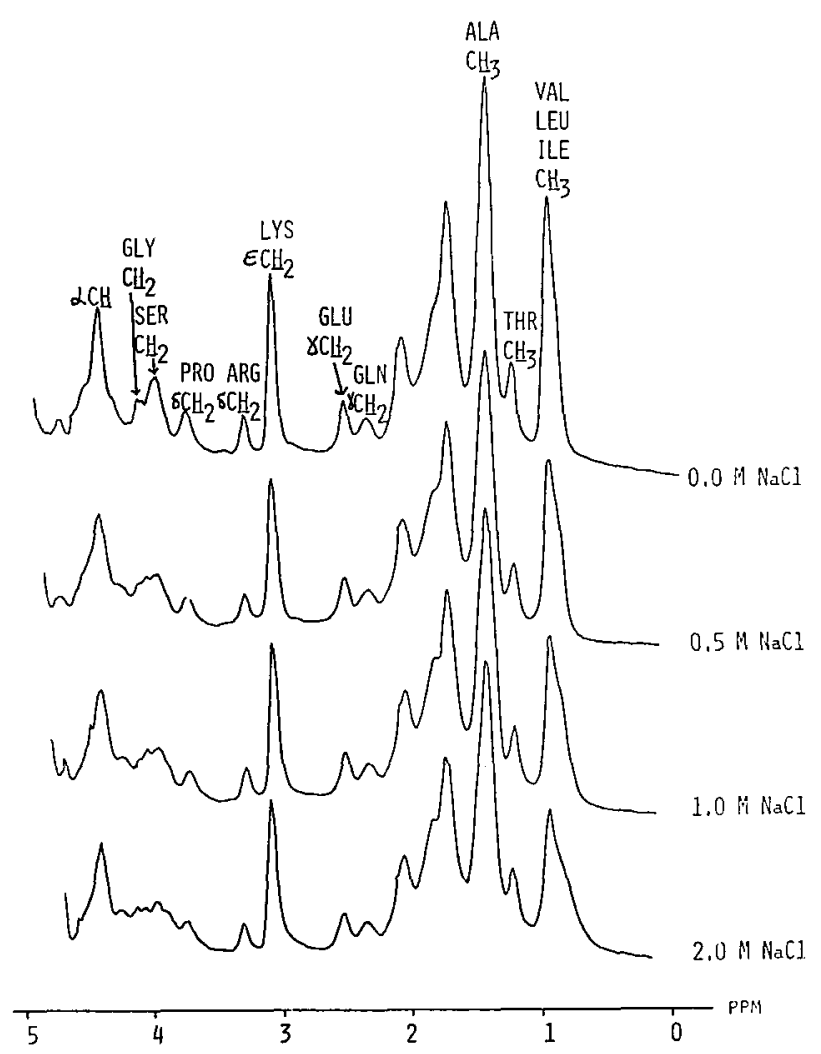

FIG. 4.
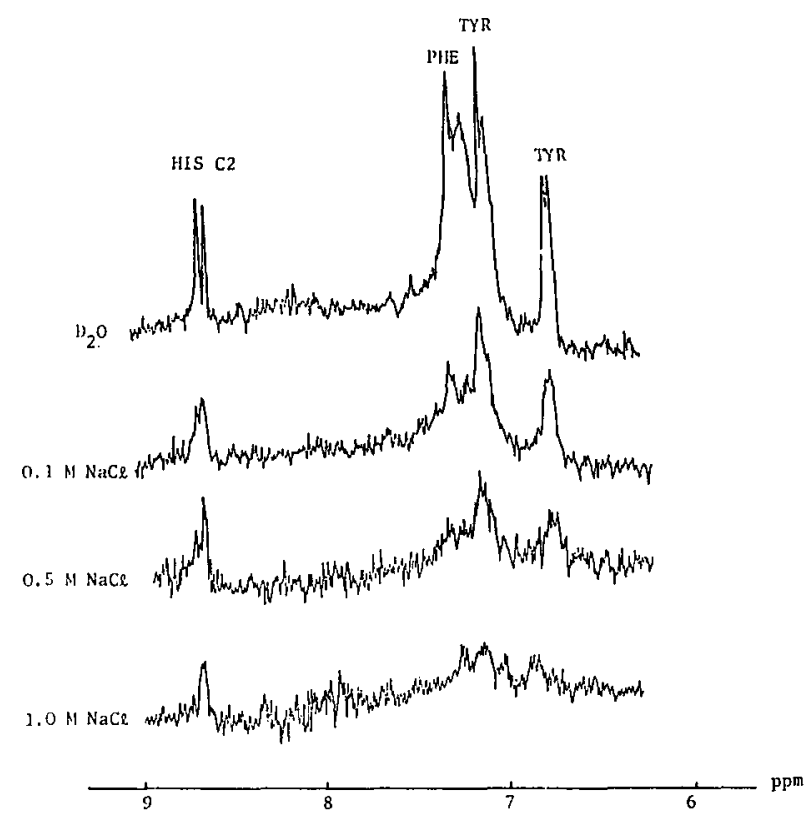

FIG. 5.

bolically inactive tissues contain lysine rich histones of higher basicity.

We have studied the interactions of calf thymus F1 and the Fl fragments $1-72$ and 73-216, chicken erythrocyte F2C and sea urchin sperm $\varphi$ 1. Partial sequence data is available for $\mathrm{F} 1$ [22], [23] and F2C [24], [25].
4. Fl and Fl fragments. - Earlier 100 and $220 \mathrm{MHz}$ NMR studies [12] of the effect of increasing ionic strength on the interactions of F1 showed that resonances from the apolar residues leucines, valines and isoleucines and the aromatic residues were broadened with a marked loss in apparent area at high salt molarity. From the composition of peptides [10] it was suggested that the segment 51 to 100 was involved in these interactions. More recently the sequence of the first 107 residues has become available [22], [23] and this partial sequence shows several very interesting features. The first 40 residues contain 14 alanines, 9 lysines, 7 prolines and 5 other random coil-favouring residues ( 3 glycines and 2 serines) to give a total of 35 , or $87 \%$, of these residues. Although the sequence of the carboxyl half 107 to 216 is unknown its amino acid composition shows that it contains $88 \%$ of the residues listed above (42 lysines, 33 alanines, 15 prolines, 5 glycines and 2 serines). The high basic charge of these end segments and their similarity of composition has led Cole and his coworkers to suggest that they are the primary sites for interaction with DNA. The intermediate segment 40 to 106 is considerably different in character from the end segments and contains 16 isoleucine and valine residues out of a total of 20 for the whole molecule and the only two aromatic resi-

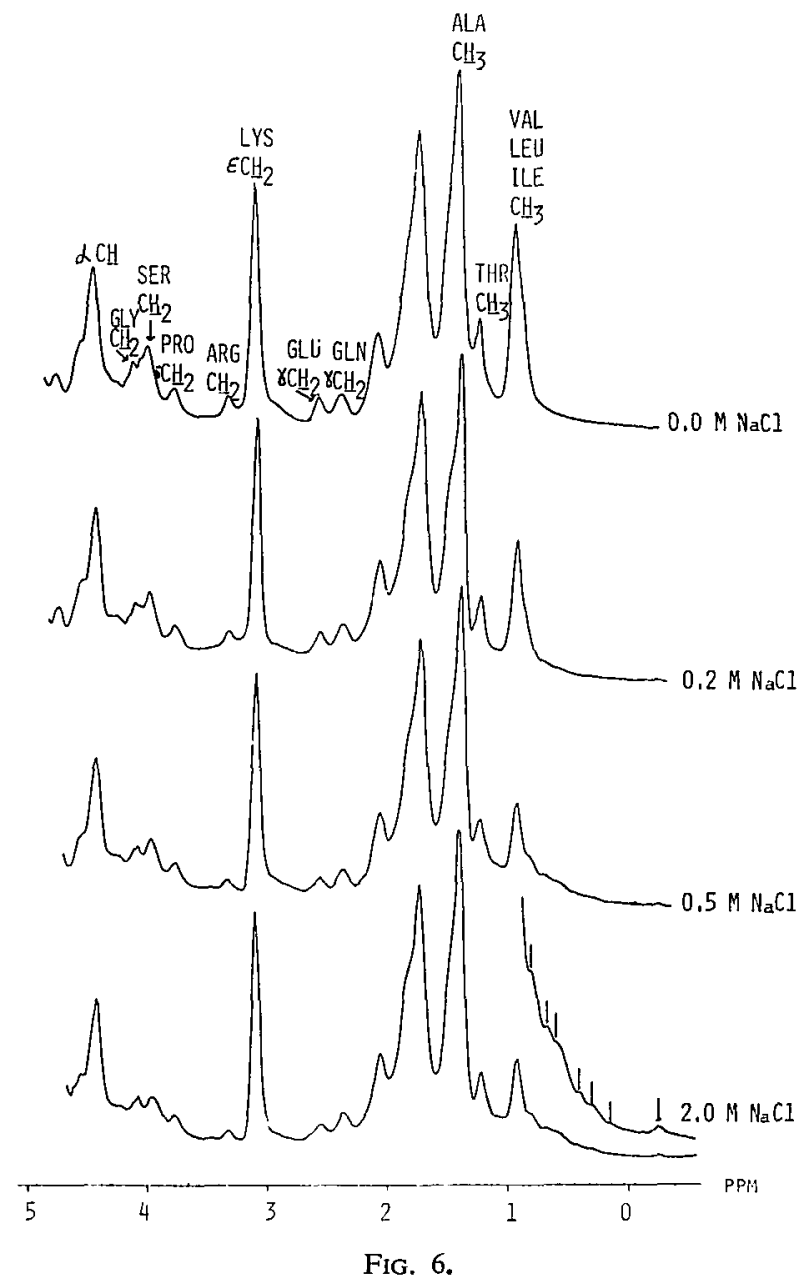


dues, tyrosine 72 and phenylalanine 106 . This segment is also appreciably less basic than the rest of the molecule. The earlier $220 \mathrm{MHz}$ data has been reevaluated and the best fit between observed and calculated spectra was obtained if resonances in the segment 47 to 106 were broadened [16]. A model for this interaction has been proposed in which segments 47 to 106 interact as antiparallel extended chains. In this scheme there are many favourable sidechain interactions between antiparallel chains.

We have reexamined calf thymus $\mathrm{F} 1$ at $270 \mathrm{MHz}$ using the Bruker 270 FT spectrometer of the Oxford Enzyme Group. The upfield spectra (Fig. 6) show, with increase in salt molarity, that as the area of the peak at $0.93 \mathrm{ppm}$ decreases weak resonances appear upfield of this peak with one resonance peak as high as $-0.24 \mathrm{ppm}$. These upfield shifted resonances result from the perturbations of the resonances of the apolar residues leucine, isoleucine and valine by particular magnetic environments in the interacted form of the Fl molecules. Some of these upfield peaks result from ring-current shifted resonances of apolar residues in the vicinity of aromatic groups and it is interesting that in the model of the $F 1$ interaction tyrosine 72 is aligned with leucine 83 and phenylalanine 106 with valine 89 . The spectrum of the aromatic residues, figure 7 , also shows additional complexity with peaks shifting as the salt molarity is increased. These differences can be attributed to particular

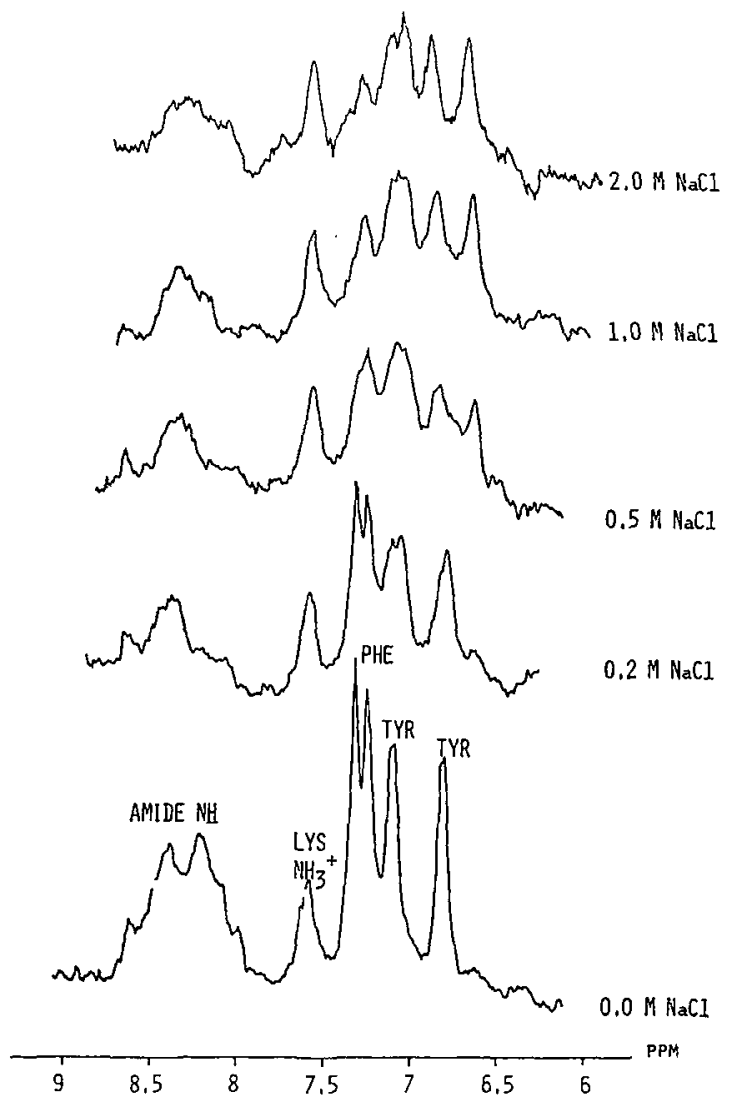

FIG. 7.

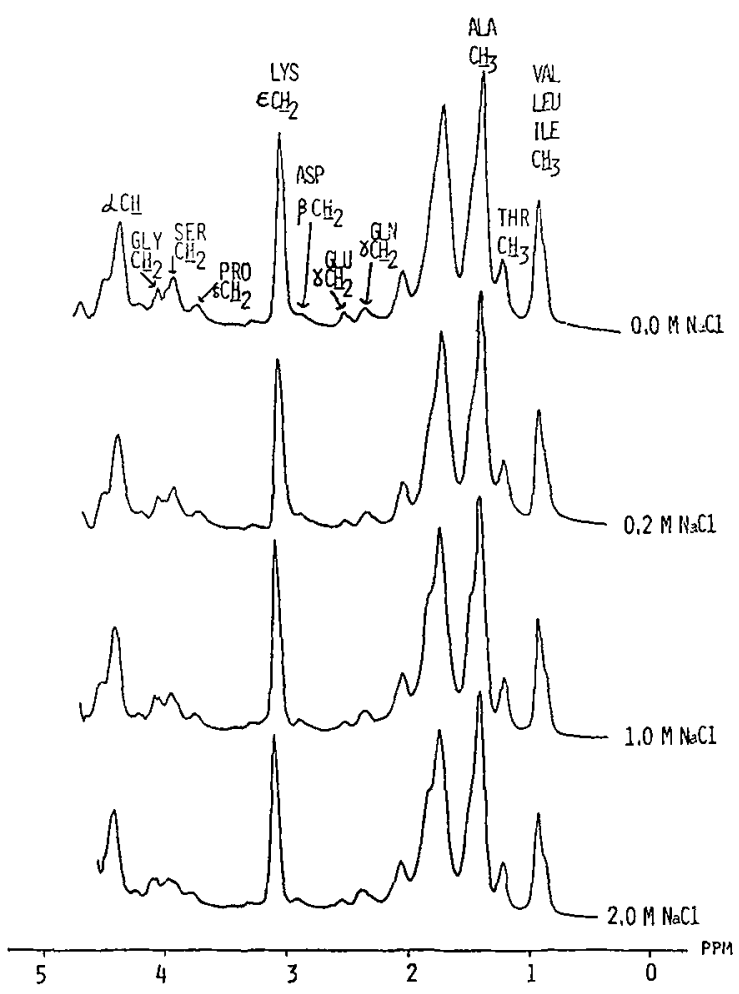

FiG. 8.

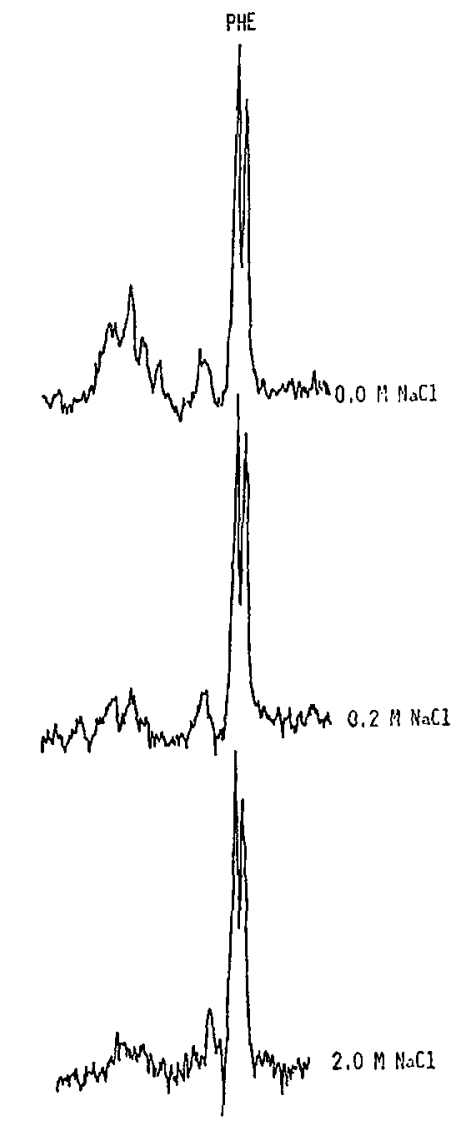

$\begin{array}{llllll}9 & 8.5 & 8 & 7.5 & 7 & 6.5\end{array}$

FIG. 9. 
environments for the aromatic residues in the interacted state of $\mathrm{F} 1$.

Fortunately, the only tyrosine residue in the F1 molecule is located almost exactly in the middle of the interacting segment at position 72 . In collaboration with J. Palau F1 has been cleaved with NBS to give the fragments $1-71$ and 73-216. The upfield and aromatic spectra of the C-terminal 73-216 are shown in figures 8 and 9. As can be seen there are no changes in the spectra even by $2.0 \mathrm{M} \mathrm{NaCl}$. This segment therefore remains fully mobile over the complete salt range and there is no evidence of any salt-induced interaction. Similarly for the N-terminal 1-72 segment except for a slight broadening of the methyl peak at $0.93 \mathrm{ppm}$ the spectrum remains unchanged by $1.0 \mathrm{M} \mathrm{NaCl}$, Figure 10 . These results

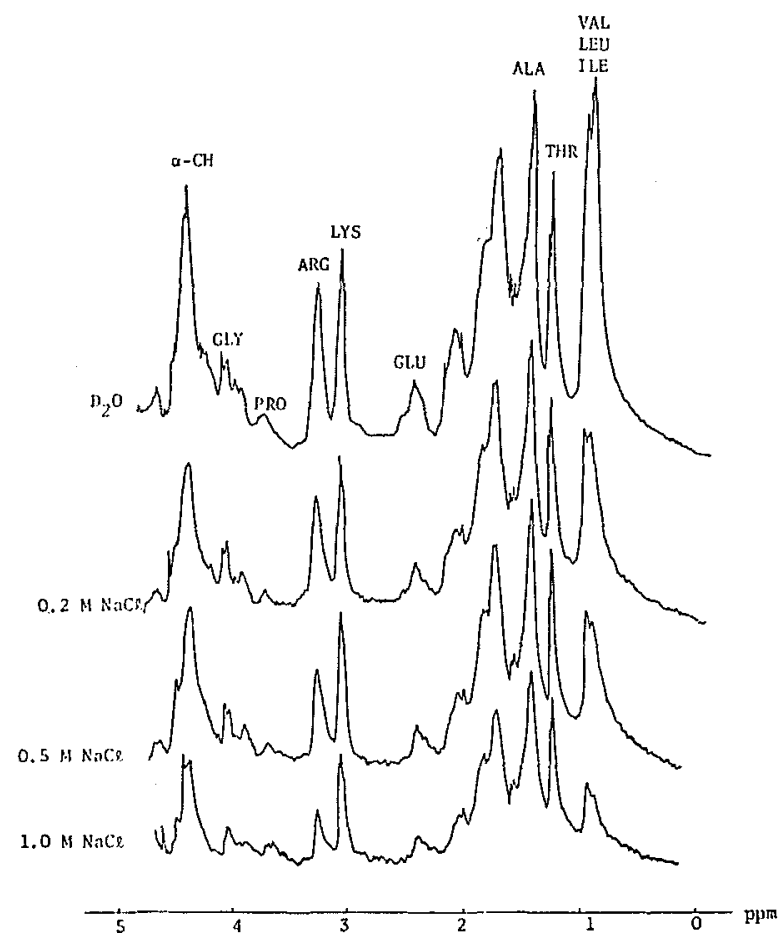

FIG. 10.

contrast with those obtained for the halves of the F2B molecules for which it was shown that both the NMR and ORD data averaged out to the behaviour of the whole molecule. It was concluded that the interactions of the half molecules were the same as those present in the whole molecule. The interactions are presumably between parallel F2B molecules so that the interaction sites remain on cleaving the molecule. In the case of F1 the absence of interactions between the fragments of molecules is consistent with the proposed model in which interactions occur between antiparallel chains. In the model segment 48 to 71 interacts with segment 84 to 106 and cleavage at tyrosine 72 isolates these interaction sites.

5. F2 C. $-\mathrm{F} 2 \mathrm{C}$ is the unique lysine rich histone fraction found in mature erythrocytes. Its compo- sition shows that it is more basic than the $\mathrm{F} 1$ histones and contains a higher proportion of arginine residues. The tentative sequence has been determined for the first 78 residues [24], [25] and this shows that unlike $\mathrm{F} 1$, there is no transition in the character of the sequence at residue 40 . In the partial sequence of F2C the apolar residues, leucines, isoleucines and valines are uniformly distributed as are most other residues. The composition data [24] shows however, that the amino third of the molecule is appreciably less basic than the carboxyl two thirds and contains most of the aromatic residues ( 2 tyrosines and 2 histidines) with 1 tyrosine and 1 phenylalanine in the carboxyl two thirds of the molecule.

This molecule provided the first indication that highly specific interactions and conformation existed for histones [27]. Figure 11 shows the $270 \mathrm{MHz}$ FT spectrum of $\mathrm{F} 2 \mathrm{C}$ in $\mathrm{D}_{2} \mathrm{O}$ and $1 \mathrm{M} \mathrm{NaCl} / \mathrm{D}_{2} \mathrm{O}$. Two striking features were observed on increase of

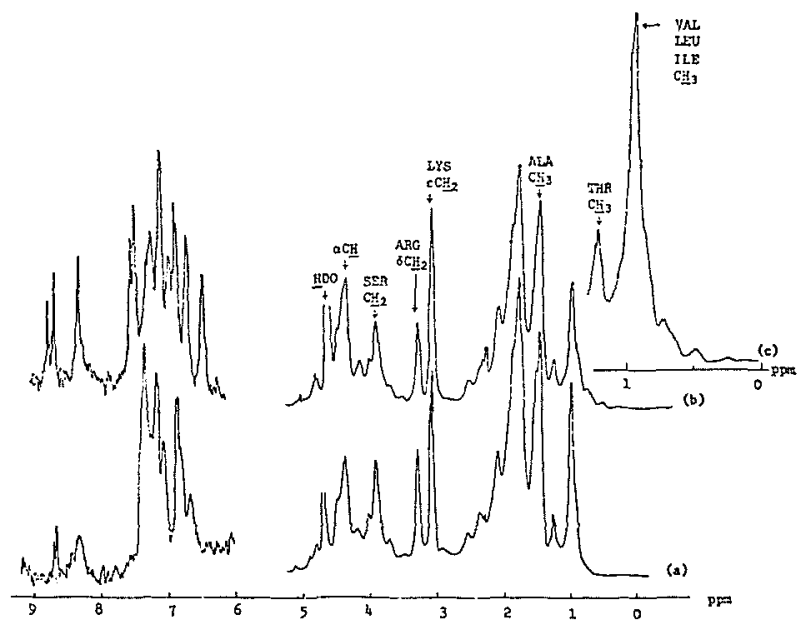

Fig. 11.

ionic strength. Firstly the marked increase in complexity of the aromatic region and secondly the appearance of ring-current shifted resonances upfield of the methyl peak at $0.93 \mathrm{ppm}$. Since spectrum $11 a$ shows some remaining perturbation of the aromatic spectrum (splitting of the histidine $\mathrm{C}-2 \mathrm{H}$ peaks at $8.7 \mathrm{ppm}$ and doubling of the tyrosine peaks (at 6.8 and $7.1 \mathrm{ppm}$ ) spectra at various concentrations were recorded at $220 \mathrm{MHz}$ and are shown, together with the effect of salt, in figure 12 . The perturbed spectrum is generated i) on increasing the concentrations of F2C in the absence of salt, e. g. from 10 to $50 \mathrm{mg}$ at $20{ }^{\circ} \mathrm{C}$, ii) on reducing the temperature of a $50 \mathrm{mg} / \mathrm{ml}$ solution from $38^{\circ}$ to $20{ }^{\circ} \mathrm{C}$ in pure water and iii) on increasing the ionic strength to $1 \mathrm{M} \mathrm{NaCl}$ of a $10 \mathrm{mg} / \mathrm{ml}$ solution. The spectral changes shown in figures 11 and 12 exactly parallel those observed when an enzyme is denatured, e. g. lysozyme and it must be concluded that intra and intermolecular interactions must occur for $\mathrm{F} 2 \mathrm{C}$ which are as specific as those found in the native forms of enzymes. 


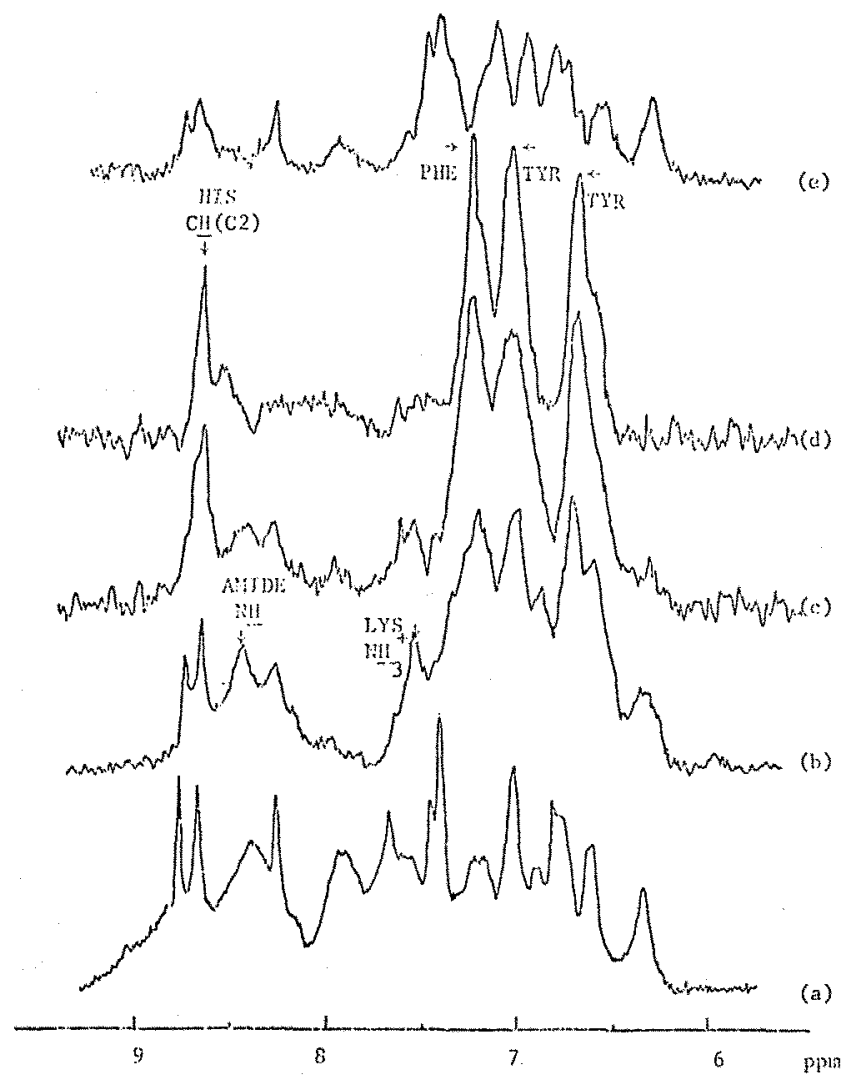

Fig. 12

6. $\varphi 1$ histone. - The lysine rich histone $\varphi 1$ from sea urchin sperm was examined because of its similarity in amino acid composition to $\mathrm{F} 2 \mathrm{C}$ and because it derives from a tissue of low metabolic activity. The NMR behaviour if however quite different to that of $\mathrm{F} 2 \mathrm{C}$. The upfield $220 \mathrm{MHz}$ spectra, figure 13, show the complete loss in apparent peak area of the upfield peak at $0.93 \mathrm{ppm}$ with increasing



FIG. 13. salt molarity. Although there is no sequence data for $\varphi 1$ it can be predicted that all of the leucines, valines and isoleucines will be found in one segment of the molecule and that this segment is the site for salt induced $\varphi 1-\varphi 1$ interactions.

7. Histone-DNA Interaction. - Studies of the interactions of histones with DNA are in progress in the following ways : i) $10 \mathrm{mg} / \mathrm{ml}$ solutions of histone and DNA in $1.6 \mathrm{M} \mathrm{NaCl} / \mathrm{D}_{2} \mathrm{O}$ are mixed together. At this salt concentration the protein and DNA are dissociated. The solution is progressively dialysed to lower salt concentrations and the NMR spectra recorded at each salt concentration until the complex precipitates from solution. On account of the necessary low concentrations of the interacting components spectra have to be time-averaged over periods of up to 12-24 hours.

ii) $3 \mathrm{mg} / \mathrm{ml}$ of DNA and $1,5 \mathrm{mg} / \mathrm{ml}$ of histone in $1.6 \mathrm{M} \mathrm{NaCl}$ are mixed and then dialysed against water. The suspension in water is dialysed back to the required salt molarity, e. g. $1.0 \mathrm{M}$ or $0.5 \mathrm{M} \mathrm{NaCl}$ and the complex centrifuged down into a pellet to leave the uncomplexed histone in the supernatant. The NMR spectrum of the pelleted gel is recorded.

8. F2B/DNA interaction. - $100 \mathrm{MHz}$ results for F2B/DNA interactions [15] show that as the salt is progressively dialysed from solution the resonance peaks from the basic regions of the polypeptide chain show a marked loss in peak area while the resonance peaks from the non-basic regions become more pronounced. The results indicate that as the DNA/ histone interactions became stronger they overcome the interchain histone-histone interactions and the segments involved in these latter interactions become more mobile; the basic regions of the histones are those involved in the histone/DNA interactions. From computer simulations [16] of the NMR spectra of F2B when complexed with DNA the best fit between observed and calculated spectra was obtained when resonances from residues in the segments 1 to 30 and 103 to 125 were broadened. It is proposed that these segments are the primary sites for interaction with DNA and it is of considerable interest that they are exactly complementary to the segment 31 to 102 which was found to be involved in salt and $\mathrm{pH}$ induced interactions of F2B molecules.

9. F2A2-DNA Interaction. - Using method (ii) described above $3 \mathrm{mg} / \mathrm{ml}$ of DNA were mixed with $1,5 \mathrm{mg} / \mathrm{ml}$ of histone both solutions in $1.6 \mathrm{M} \mathrm{NaCl}$ solution. The mixture was dialysed down to water, centrifuged and the gel resuspended and dialysed back to $1.0 \mathrm{M}, 0.8 \mathrm{M}, 0.6 \mathrm{M}, 0.4 \mathrm{M} \mathrm{NaCl}$, etc. At each salt molarity the suspension was centrifuged and the NMR spectrum of the gel recorded. Interactions between F2A2 and DNA were observed over the whole salt range. In the salt induced self-interaction of F2A2 described earlier it was shown that with 


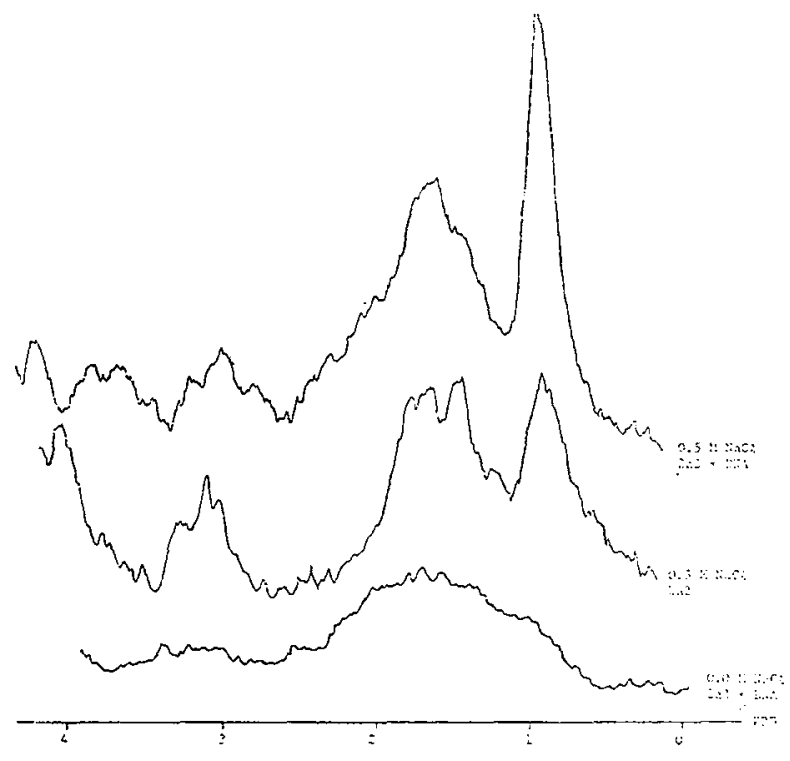

FIg. 14.

increase in salt molarity the resonance peaks from the apolar residues, the acidic residues and the tyrosines, phenylalanine and some of the histidines were broadened and showed marked loss of apparent peak area. On interaction of F2A2 with DNA it was found, figure 14, that the peaks which were affected in the salt-induced self interactions became the most prominent and this suggested, as for F2B, that it is the basic segments of F2A2 which are not involved in the self interaction, which bind to DNA. Computer simulation of spectra are in progress.

10. F2A1-DNA interactions. - Preliminary studies have been carried out at $100 \mathrm{MHz}$. Because of the insolubility of high concentrations of F2A1 in high salt very low concentration of the interacting components were used $; 0.1 \mathrm{mg} / \mathrm{ml}$ of DNA and $0.05 \mathrm{mg} / \mathrm{ml}$

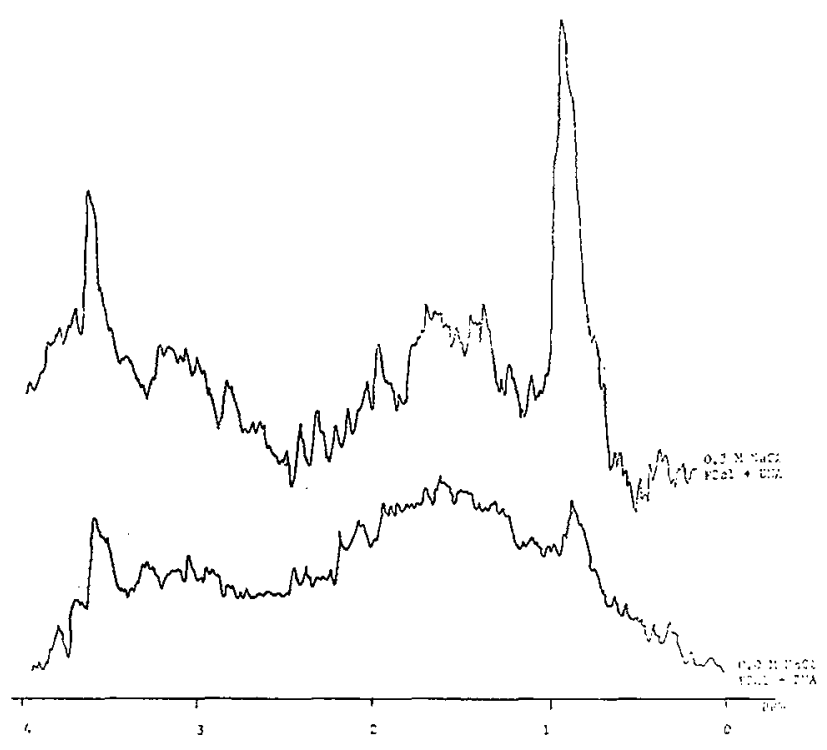

FIG. 15. of F2Al were mixed at $1.6 \mathrm{M} \mathrm{NaCl}$ and dialysed to the required salt molarity. The complex was then concentrated into a gel by centrifugation and the NMR spectra of the gel recorded. The upfield $100 \mathrm{MHz}$ spectra are shown in figure 15 . It can be seen that the most prominent peak in the presence of DNA is from the methyl groups of the apolar residues at $0.93 \mathrm{ppm}$ while the resonances from the sidechains of the basic residues are much reduced. This demonstrates that the very basic segment of F2Al is bound to DNA while the carboxyl half of the molecule which is rich in apolar residues has become mobile. These preliminary results suggest, similar to F2B and $F 2 A 2$, that the basic segments of F2A1 are the primary binding site to DNA while the apolar segments are the sites for histone-histone interactions as found for the salt induced interaction.

11. F1-DNA interactions. - Early $100 \mathrm{MHz}$ results [15] suggested that, in contrast to the behaviour of the other histones, the whole of the F1 molecule became bound to the DNA. In these studies no differential behaviour was observed in the NMR spectrum on dialysing fromhigh to low salt, the whole NMR spectrum of Fl simply becoming weaker, These observations have now been repeated twice with the same results. The binding of the two fragments 1 to 71 and 73 to 216 to DNA has also been studied and in a similar manner the whole spectrum for each fragment weakens as the salt molarity is reduced. It appears from these studies that the whole of $\mathrm{F} 1$ and of fragments of F1 becomes stabilised by the interaction with DNA at low salt. It was throught however that the interaction sites available to F1 molecules in the nucleoprotein complex are those provided by the complex of DNA with the otherhistones and that the interactions of F1 with pure DNA may not be a realistic model. As mentioned earlier there are several reasons why the lysine rich histones should be considered as different to the other histones. One of these was the observation that although they are the most basic of the histones they are the first to be dissociated from the nucleoprotein complex on increasing the salt molarity. By $0.6 \mathrm{M} \mathrm{NaCl}$ the lysine rich histones are completely dissociated while the other histones remain bound in the complex. This observation prompted us to record NMR spectra of the nucleoprotein gel over the range of salt molarities from water to $0.6 \mathrm{M} \mathrm{NaCl}$.

Note added in proof. - More recent results at $270 \mathrm{MHz}$ have revealed that there are in fact differential broadening effects in the spectrum of $\mathrm{Fl}$ interacted with DNA, and these are currently the subject of further investigation.

12. F1 interactions in chromatin Gel. - Chromatin in water is a diffuse fibrous gel. Increasing the salt molarity to 0.1 to $0.2 \mathrm{M} \mathrm{NaCl}$ causes a contraction of the gel to $13 \%$ of ist original volume [28]. As the 
molarity is increased above $0.3 \mathrm{M} \mathrm{NaCl}$ the gel disperses and by $0.6 \mathrm{M} \mathrm{NaCl}$ the F1 molecules are dissociated and the gel has become fully dispersed. NMR spectra recorded on this range of salt molarities are shown in figure 16. Unlike the interaction of $\mathrm{Fl}$ with DNA these spectra show differential broadening effects. Figure $16 a$ is the control and shows the signals from $F 1$ depleted nucleoprotein in $0.6 \mathrm{M} \mathrm{NaCl}$. Only weak broadened resonances are observed and it is assumed that in the range of salt molarities 0 to $0.6 \mathrm{M} \mathrm{NaCl}$ the NMR signals from the gel will come only from the FI molecules. The almost complete absence of signal in $16 \mathrm{~b}$ indicates that in the non-condensed gel in $\mathrm{D}_{2} \mathrm{O}$, virtually all the histones are bound firmly to the complex, broadening their signals which results in almost the complete absence of a visible spectrum. The addition of $0.1 \mathrm{M} \mathrm{NaCl}(16 c)$, which is accompanied by gel

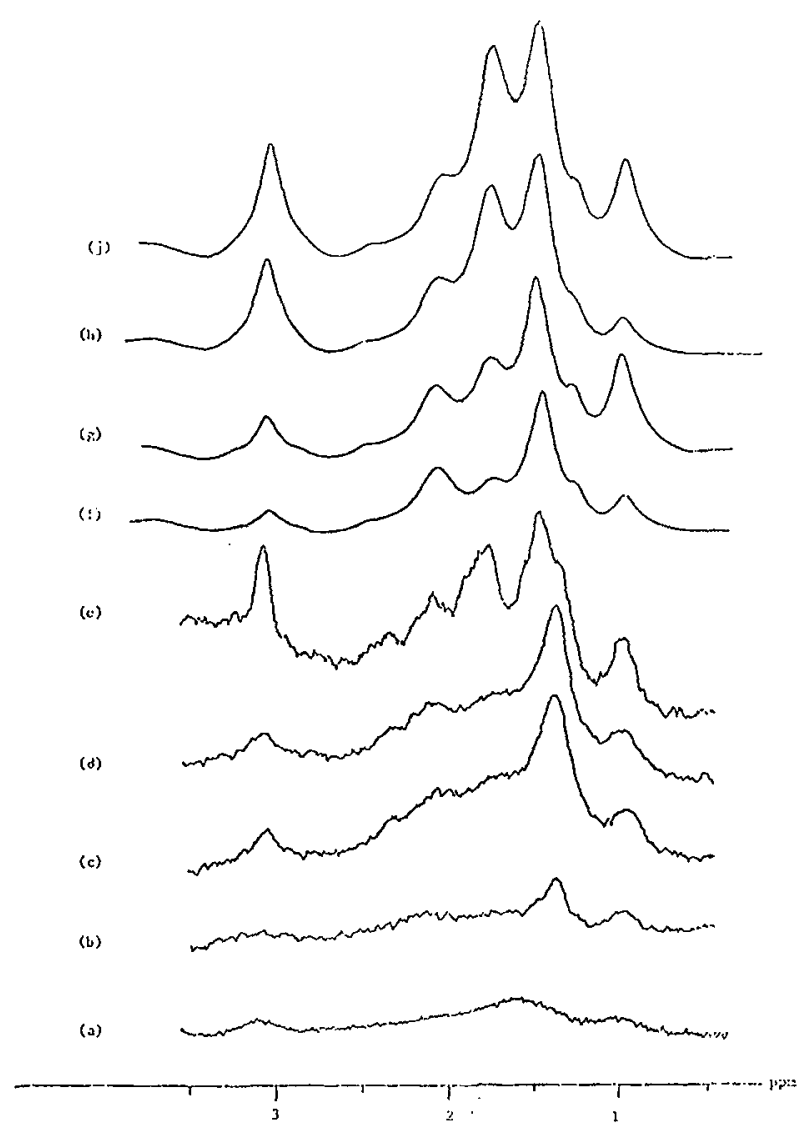

FIG. 16.

condensation, causes a large change in the spectrum ; peaks appear which correspond mainly to alanine, proline and a few lysine residues, with very little other observable changes. Increasing salt to $0.25 \mathrm{M}$ $(16 d)$ produced very little change either in the spectrum, or in the state of gel condensation, but a further increase to $0.5 \mathrm{M}(16 e)$, which corresponds both to complete re-expansion of the gel and to complete removal of the $F 1$, yields a spectrum which is identical to that of $\mathrm{Fl}$ in $0.5 \mathrm{M} \mathrm{NaCl}$, with the sole difference that all the linewidths are broader by a factor of approximately 1.8 .

The most remarkable change in the spectrum between 0.25 and $0.5 \mathrm{M} \mathrm{NaCl}$ is the sudden appearance of the lysine peaks at an ionic strength which corresponds with the release of F1 from the DNP complex. Figure $16 f$ shows that the spectrum observed for DNP at 0.1 or $0.15 \mathrm{M} \mathrm{NaCl}$ may be closely approximated by the simulation of the $F$ l spectrum at these ionic strengths. but with about 40 of the 60 lysine residues removed from the spectrum, these being present in the carboxyl half of the histone. It is important at this stage also to note that the simulations of the $\mathrm{F} 1$ spectrum at $0.1 \mathrm{M}$ and $0.25 \mathrm{M} \mathrm{NaCl} 16 \mathrm{c}$ and $16 \mathrm{~d}$ also include the changes brought about by the association of the section 47-106 of the Fl molecules.

We may therefore draw the following conclusions from the spectra of figure 16 :

a) Under the salt conditions used. no spectrum appears which is not directly attributable to the molecules of $F 1$ in the complex. Removal of F1 also removes almost the entire observable spectrum (Fig. 16a) even at a sodium chloride concentration at which a spectrum is very apparent in total DNP. The implication of this result is that all the remaining components of the system (the other histone fractions, DNA and acidic proteins) are too rigid throughout the experiment to give a high-resolution spectrum. A corollary of this conclusion is that the spectrum of F1 or parts of F1 must only be observable as long as those parts are not bound to the rigid complex.


FIG. 17. 
b) Under conditions of low ionic strength, where there is no condensation of the gel, all the $F$ quite firmly bound to the complex.

c) Under conditions corresponding to gel condensation, most of the lysines of the Fl are firmly bound, and the spectrum which is visible corresponds to that obtained when an Fl-Fl interaction of residues 47-106 is taking place (compare fig. c) and $f$ )).

d) Complete removal of the $F 1$ produces re-expansion of the gel and a freeing of the lysine residues. The spectrum obtained still includes the interaction of residues 47-106.

An important conclusion of this study is that the segment of F 1 47-106 which interacts in the chromatin gel when condensation of the gel takes place between 0.1 to $0.2 \mathrm{M} \mathrm{NaCl}$, is the same segment of $\mathrm{Fl}$ which is involved in the salt-induced interactions of the pure histone in aqueous solutions. The results described above lead to the model shown in figure 17 for the interactions of $F 1$ molecules in the condensation of the chromatin gel at 0.1 to $0.2 \mathrm{M}$ $\mathrm{NaCl}$.

13. Conclusions. - The above work convincingly demonstrates the power of the technique of high resolution NMR in probing the conformations and interactions of histones $a$ ) with themselves, $b$ ) with DNA and $c$ ) in chromatin gel. The application of the technique is a consequence of the asymmetric distribution of residues in the histone molecules and uses these residues as probes. A general picture is emerging in which segments of histones rich in basic residues are the primary sites of interaction with DNA while the complementary segments which contain a high proportion of apolar aromatic, acidic and other active residues are the sites of histone interactions. It is possible through such interactions to envisage schemes whereby the conformation of DNA could be controlled in the interphase and métaphase chromosome. Large changes in state of chromatin gel can be induced by small changes of salt molarity of 0.1 to $0.2 \mathrm{M} \mathrm{NaCl}$. The interactions of the $\mathrm{Fl}$ molecules have been followed in the chromatin gel through these salt changes and this has led to the first detailed proposal concerning a structural role for the lysine rich histones. It may also be significant that the self-interactions of other histones can be induced at relatively low salt molarities.

Acknowledgments. - The authors gratefully acknowledge the continuing and generous support of the Science Research Council of Great Britain.

\section{References}

[1] Stedman, E. and Stedman, E., Nature 166 (1950) 780.

[2] Sautiere, P., Breynaert, M., Moschetro, Y. and Biserte, G., C. R. Hebd. Seanc. Acad. Sci. Paris 271 (1970) 364.

[3] Delange, R. J., Fambrough, D. M., Smith, E. L. and BONner, J., J. Biol. Chem. 244 (1969) 319.

[4] Delange, R. J., Fambrough, D. M., Smith, E. L. and BONNER, J., J. Biol. Chem. 244 (1969) 5669.

[5] ZubaY, G. and Wilkins, M. H. F., J. Mol. Biol. 4 (1962) 444.

[6] IWai, K., Ishikawa, K. and Hayashi, H., Nature 226 (1970) 1056.

[7] Busch, H., Private communication.

[8] Sautiere, P., Private communication.

[9] Delange, R. J., Hooper, J. A. and Smith, E. L., PNAS 69 (1972) 882.

[10] Bustin, M., Rall, S. C., Stellwagen, R. H. and COLE, R. D., Science 163 (1969) 391.

[11] Jones, P. N. and Scheraga, H. A., Arch. Biochem. and Biophy's. 144 (1971) 584.

[12] Boublik, M., Bradbury, E. M. and Crane-Robinson, C., Elur. J. Biochem. 14 (1970) 486.

[13] Boublik, M., Bradbury, E. M., Crane-Robinson, C. and JoHns, E. W., Eur. J. Biochem. 17 (1970) 151.

[14] Bradbury, E. M., Crane-Robinson, C., Goldman, H., Ratrle, H. W. E. and Stephens, R. M., J. Mol. Biol. 29 (1967) 507.

[15] Boublik, M., Bradbury, E. M., Crane-Robinson, C. and Rattle, H. W. E., Nature 229 (1971) 149.

[16] Bradbury, E. M. and Rattle, H. W. E., Elir. J. Biochem, 27 (1972) 270.

[17] Bradbury, E. M., Crane-Robinson, C., Phillips, D. M. P., Johns, E. W. and Murray, K., Nattre 205 (1965) 1315.

[18] Bradbury, E. M., Cary, P. D., Crane-Robinson, C., Riches, P. and Johns, E. W., Eur. J. Biochem. 26 (1972) 482.
[19] Bradbury, E. M., Crane-Robinson, C., Rattle, H. W. E. and STEPhens, R. M., Conformations of Biopolymers Ed. Ramachandran 2 (1967) 583.

[20] KinCade, J. M. and Cole, R. D., J. Biol. Chem. 241 (1966) 5799.

[21] Palau, J., Ruiz-Carillo, A., Subirana, J. A., Eur, $J$. Biochem. 7 (1969) 209.

[22] Rall, S. C. and Cole, R. D., J. Biol. Chem. In Press.

[23] Cole, R. D. and Jones (Private communication).

[24] Greenaway, P. J. and Murray, K., Nature New Biol. 229 (1971) 233.

[25] Greenaway, P. J., Ph. D., Thesis Edinburgh University (1970).

[26] Bustin, M., Rall, S. C., Stellwagen, R. H. and Cole, R. D., Science 163 (1966) 391.

[27] Bradbury, E. M., Crane-Robinson C. and Johns, E. W., Nature In Press.

[28] Bradbury, E. M., Carpentier, B. G. and Rattle, H. W. E. Submitted to Natme.

[29] Allfrey, V. G., in "Histones and Nucleohistones》 ed. D. M. P. Phillips (1971), Plenum Press, (1971) London New York.

[30] Bradbury, E. M., Inglis, R. J., Matthews, H. R. and Sarner, N., Submitted to Eur. J. Biochem.

[31] Bradbury, E. M., Molgaard, H. V., Stephens, R. M.. Bolund, L. and Johns, E. W., Submitted to Eur. $J$. Biochem.

[32] Sung, M. and Dixon, G. H., PNAS 67 (1970) 1616.

[33] Candido, E. M. P. and Dixon, G. H., J. Biol. Chem. 247 (1972) 3868.

[34] Candido, E. M. P. and Dixon, G. H., J. Biol. Chem. 246 (1971) 3182.

[35] Terhorst, C., Wittman-Liebold, B. and Moller, W., Eur. J. Biochem. 25 (1972) 13-19. 
[36] Moller, W., Groene, A., Terhorst, C. and Amms, R., Eur. J. Biochem 25 (1972) 1-12.

[37] Kaltschmidt, E. and Wirtman, H. G., PNAS (USA) 67 (1970) 1276

[38] Kischa, K., Moller, W. and Stoffler, G., Nature (New Biol) 233 (1971) 62.

[39] Boublik, M., Brot, N. and Weissbach, H., PNAS (USA) In Press August 1972

[40] Bradbury, E. M. and Rattle, H. W. E., Polymer 9 (1968) 201.

[41] Bradbury, E. M., Crane-Robinson, C., Goldman, H. and RatTle, H. W. E., Biopolymers 6 (1968) 851.

[42] Bradbury, E. M., Carpenter, B. G., Crane-Robinson, C. and Rattle, H. W. E., Nature 220 (1968) 69.

[43] Bradbury, E. M., Crane-Robinson, C., Goldman, H. and Rattle, H. W. E., Nature 217 (1968) 812.

[44] Boublik, M., Bradbury, E. M., Crane-Robinson, C. and RATTLE, H. W. E., Eur. J. Biochem. 12 (1970) 258.

[45] Sheard, B. and Bradbury, E. M., Progress in Biophysics and Molecular Biology 20 (1970) 187.
[46] Bradbury, E. M., Crane-Robinson, C. and Rattle, H. W. E., Polymer 11 (1970) 277.

[47] Bradiury, E. M., Carpenter, B. G., Crane-Robinson, C. and Goldman, H., Nature 225 (1970) 64.

[48] Braduury, E. M., Carpenter, B. G., Crane-Robinson, C. and Goldman, H., Macromolecules 4 (1971) 557.

[49] Bradbury, E. M., Cary, P., Crane-Robinson, C., Paolillo, L., Tancredi, T. and Temussi, P. A., J. Am. Chem. Soc. 93 (1971) 5916.

[50] Paolillo, L., Temussi, P., Trivellone, E., Bradrury, E. M. and Crane-Robinson, C., Biopolymers 10 (1971) 2555

[51] Paolillo, L., Tancredi, T., Temussi, P. A., Trivellone, E., Bradbury, E. M. and Crane-Robinson, C., J. C. S. Chem. Comm. (1972) 335.

[52] Bradbury, E. M., Crane-Robinson, C., Giancotti, V. and STEPhens, R. M., Biopolymers 13 (1972) 33.

[53] Paolillo, L., Temussi, P. A., Bradbury, E. M. and CraneRobinson, C., Biopolymers In Press 1972. 